\title{
A comparative study of hemodynamic changes in dexmedetomidine versus midazolam and fentanyl combination during awake fibreoptic intubation
}

\author{
Ritu Baloda', Jaspreet Kaur ${ }^{2}$, Rupali Battu ${ }^{3}$, Sudha Puhal ${ }^{4}$ \\ ${ }^{1,4}$ Assistant Professor, Pandit Bhagwat Dayal Sharma Post Graduate Institute of Medical Sciences, Rohtak, Haryana, \\ ${ }^{2}$ Assistant Professor, Punjab Institute of Medical Sciences, Jalandhar, Punjab, ${ }^{3}$ Senior Resident, VMMC and \\ Safdarjung Hospital, New Delhi, India
}

\section{A B S T R A C T}

Background: The hemodynamic changes during awake fibreoptic intubation (AFOI) are attributed to patient's anxiety, poor topicalization of the airway, excessive sedation, lack of expertise, pain, prolonged time to intubation, stimulation of oropharyngeal structures, and jaw thrust to aid intubation. In this study, we compared hemodynamic changes of dexmedetomidine (DEX) with midazolam (MDZ) and fentanyl during AFOI. Aims and Objectives: The objective of the study is to compare the hemodynamic changes in DEX alone versus fentanyl- MDZ combination during AFOI. Materials and Methods: Group-I patients $(n=30)$ received DEX $1 \mu \mathrm{g} / \mathrm{kg}$ bolus infusion over $10 \mathrm{~min}$, followed by infusion of $0.1 \mu \mathrm{g} / \mathrm{kg} / \mathrm{h}$ titrated to $0.7 \mu \mathrm{g} / \mathrm{kg} / \mathrm{h}$ whereas Group-II patients $(\mathrm{n}=30$ ) received iv fentanyl $2 \mu \mathrm{g} / \mathrm{kg}$ bolus followed by MDZ infusion of $0.02-0.1 \mathrm{mg} / \mathrm{kg} / \mathrm{h}$ until they were adequately sedated, i.e. Ramsay Sedation Score (RSS) of 3. Hemodynamics including heart rate (HR), systolic blood pressure (SBP), diastolic blood pressure (DBP), oxygen saturation $\left(\mathrm{SpO}_{2}\right)$ were recorded when patient is sedated, i.e. at RSS-3, every min of fibrescopy till 5 min and at intubation and every $3^{\text {rd }}$ min post-intubation till 30 min. Results: Measurements of the HRs in the two groups showed significant differences between the two groups at RSS-3, during FOS and post-intubation with the DEX group showing lower mean HRs compared with the MDZ and fentanyl group. SBP and DBP showed a fall in both the groups as compared with the baseline at RSS-3, during FOS and post-intubation; however, no significant differences were noted between the two groups. The mean $\mathrm{SpO}_{2}$ values show significant difference between the two groups. $(P<0.05)$ at RSS-3, FOS, post intubation upto 18 min $(P<0.05)$. Conclusion: The use of DEX at $1 \mathrm{mcg} / \mathrm{kg}$ bolus slowly over $10 \mathrm{~min}$, with maintenance rates of $0.1-0.7 \mu \mathrm{g} / \mathrm{kg} / \mathrm{h}$, is safe and beneficial for patients undergoing AFOI. Thus, DEX acts like an ideal drug for AFOI. It provides excellent intubating conditions without significant hemodynamic perturbations and risk of hypoxia.

\section{Access this article online}

Website:

http://nepjol.info/index.php/AJMS DOI: 10.3126/ajms.v12i11.38993

E-ISSN: 2091-0576

P-ISSN: 2467-9100

\section{Copyright (c) 2021 Asian Journal of} Medical Sciences

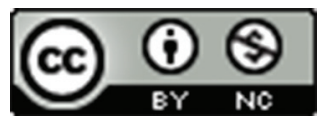

This work is licensed under a Creative Commons Attribution-NonCommercial 4.0 International License.

Key words: Awake fibreoptic intubation; Dexmedetomidine; Fentanyl; Midazolam

\section{INTRODUCTION}

Hemodynamic response to laryngoscopy and intubation was first described by Reid and Brace in 1940. Healthy individuals are able to tolerate it well, but these changes may prove to be fatal in high-risk patients. ${ }^{1,2}$
The hemodynamic changes during awake fibreoptic intubation (AFOI) are attributed to patient's anxiety, poor topicalization of the airway, excessive sedation, lack of expertise, pain, prolonged time to intubation, stimulation of oropharyngeal structures, and jaw thrust to aid intubation. ${ }^{3}$ 
Thus, drugs used for blunting of this response must have analgesic, sedative, amnesic, and sympatholytic properties. Various drugs have been tried in the recent past, including benzodiazepines such as midazolam (MDZ), opioids such as fentanyl, sufentanil, ramifentanil, sedative hypnotics such as propofol, ketamine, alpha-2 agonists such as clonidine and dexmedetomidine (DEX) $\cdot{ }^{47}$ DEX, revolutionized the concept of sedation in AFOI. Sedation without airway obstruction and respiratory depression is a unique feature of DEX. ${ }^{8}$

During AFOI deep sedation may lead to apnea but very light sedation may have adverse cardiovascular consequences in form of hypertension and tachycardia, especially in high-risk patients. Hence, an ideal sedative is expected to provide comfort and elicit patient's cooperation while maintaining hemodynamic stability and spontaneous ventilation.

Due to risk of respiratory depression and poor analgesia, benzodiazepines alone are not a good choice for AFOI. Fentanyl on the other hand helps to attenuate pressor response to intubation when used in combination with BZP. In this study, we compared hemodynamic changes of DEX with MDZ and fentanyl during AFOI.

\section{Aims and objectives}

To compare the hemodynamic changes in DEX alone versus fentanyl-MDZ combination during AFOI.

\section{MATERIALS AND METHODS}

After the Institutional Ethical Committee approval, the study was conducted in Government Medical College, Patiala in 60 patients aged between 18 and 60 years, ASA Grade I and II scheduled for elective surgery. A written informed consent was obtained from each patient. The patients were randomly divided into two groups of 30 each.

\section{Exclusion criteria}

Patient's refusal, baseline heart rate $(\mathrm{HR})<60$, baseline blood pressure $<100 / 50$, coagulopathy, history of nasal surgery/nasal trauma, nasal polyp, cardiovascular disease, liver cirrhosis, alcohol and drug abusers, mentally ill patients, allergic to the drugs used in the study, patients on drugs such as digitalis, beta-blockers, and calcium channel blockers are known to produce changes in HR and blood pressure.

Pre-anesthetic checkup was done in every patient. All patients were given injection. Glycopyrrolate $(0.2 \mathrm{mg})$ i.m $30 \mathrm{~min}$ before the elective surgery. Baseline vital parameters of all the patients such as HR, systolic blood pressure (SBP), diastolic blood pressure (DBP), and oxygen saturation $\left(\mathrm{SpO}_{2}\right)$ were documented.
Group-I patients ( $\mathrm{n}=30)$ were received DEX $1 \mu \mathrm{g} / \mathrm{kg}$ bolus infusion over $10 \mathrm{~min}$, followed by an infusion of $0.1 \mu \mathrm{g} / \mathrm{kg} / \mathrm{h}$ titrated to $0.7 \mu \mathrm{g} / \mathrm{kg} / \mathrm{h}$ until they are adequately sedated, i.e., Ramsay Sedation Score (RSS) of 3.

Group-II patients ( $\mathrm{n}=30$ ) were received iv fentanyl $2 \mu \mathrm{g} / \mathrm{kg}$ bolus followed by MDZ infusion of $0.02-0.1 \mathrm{mg} / \mathrm{kg} / \mathrm{h}$ until they are adequately sedated, i.e., RSS of 3 .

Patients were placed in the supine position. Each nostril was checked for patency. The nostril with least resistance was chosen for nasal intubation. Nasal mucosa was sprayed with vasoconstrictor xylometazoline $(0.1 \%)$ and with two puffs of $10 \%$ lignocaine. $2 \%$ lignocaine viscous gargles were done to achieve adequate topical anesthesia. For further topical anesthesia two puffs of $10 \%$ lignocaine were sprayed over tonsillar pillars and back of the throat. Spray as you go technique was used for airway topicalization. When fiberscope reached up to the vocal cords, $2 \mathrm{ml}$ of $2 \%$ lignocaine with some air was injected through the epidural catheter inserted over the working channel of the fiberscope. After crossing vocal cords $2 \mathrm{ml}$ of $2 \%$ lignocaine with some air was injected in the upper part of the trachea. Supplemental doses of lignocaine up to a maximum of $9 \mathrm{mg} / \mathrm{kg}$ were administered to the airway. On reaching the carina endotracheal tube was railroaded over the fibrescope. The endotracheal tube was secured and G.A was administered. Hemodynamics including HR, SBP, diastolic blood pressure, $\mathrm{SpO}_{2}$ were recorded when patient is sedated, i.e. at RSS-3, every min of fibrescopy till $5 \mathrm{~min}$ and at intubation, and every $3^{\text {rd }}$ min post-intubation till $30 \mathrm{~min}$. The surgical procedure was then proceeded as planned.

\section{Statistical analysis}

The results obtained in the study were analyzed using IBM SPSS statistics software version 20.0. Statistical analysis was carried out using Student's t-test. Hemodynamic variables were expressed as Mean \pm SD. $\mathrm{P}<0.05$ was regarded as statistically significant, and $\mathrm{P}>0.05$ was regarded as non-significant.

\section{Observations}

Age : The mean age of patients in group 1 and 2 was $43.80 \pm 12.3$ years and $40.50 \pm 12.06$ years, respectively. The difference was statistically insignificant $(p>0.05)$. (Figure 1). Both the groups had predominance of females but the sex ratio was comparable in both groups. ( $p>0.05$ ). (Figure 2$)$.

\section{BASELINE HEART RATE}

The mean heart rate (mean \pm S.D) at baseline was $82.7 \pm 8.07$ in group 1 and $83.77 \pm 7.30$ in group 2. There was no statistically significant difference between the two groups at baseline. ( $p>0.05)$. (Figure 3) 


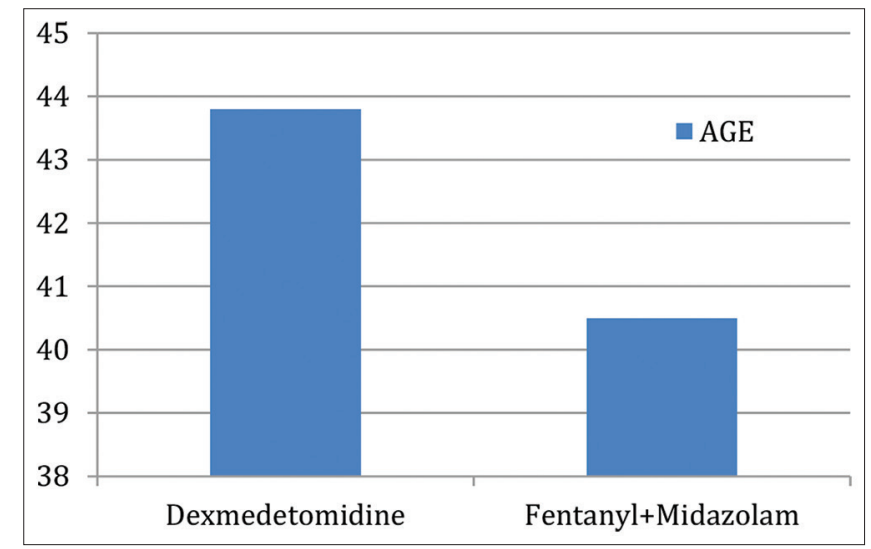

Figure 1: Age distribution in both groups

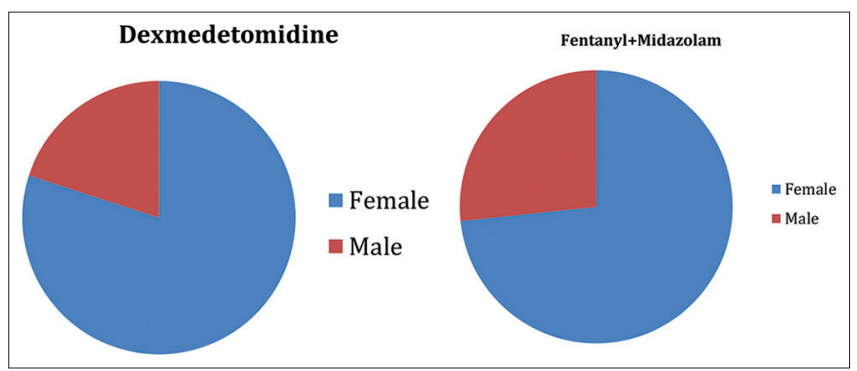

Figure 2: Gender distribution in both groups

\section{AT RSS 3}

The mean heart rate at RSS 3 was $75.50 \pm 7.39$ in group 1 and $81.97 \pm 9.06$ in group 2 . The difference in heart rate between the two groups was statistically significant $(\mathrm{p}<0.05)$. (Figure 3).

Compared with baseline, the mean heart rate decreased by 7.2 beats/min in the dexmedetomidine group and 1.8 beats / min in fentanyl and midazolam group. This decline in heart rate was statistically significant for dexmedetomidine group $(\mathrm{p}<0.001)$; whereas it was statistically insignificant for fentanyl and midazolam group $(p=0.072)$.Compared with baseline, the mean heart rate at the time of insertion of fiberoscope ( 0 min) decreased by 11.83 beats $/ \mathrm{min}$ in the dexmedetomidine group and 7.63 beats/min in fentanyl and midazolam group. The fall in heart rate for both groups was statistically significant $(\mathrm{p}<0.001)$.

On comparison between the 2 groups, significant differences were found in heart rate during FOS $(\mathrm{p}<0.05)$ (Figure 3) Compared with baseline, the mean heart rate at the time of intubation ( $0 \mathrm{~min}$ ) decreased by 15.06 beats $/ \mathrm{min}$ in the dexmedetomidine group and 12.83 beats/min in fentanyl and midazolam group. The fall in heart rate for both groups was statistically significant $(\mathrm{p}<0.001)$. On comparison between the 2 groups, significant differences were found in the heart rate after endotracheal intubation upto 15 mins $(p<0.05)$ after which the difference was statistically insignificant ( $\mathrm{p}>0.05)$ (Figure 3).

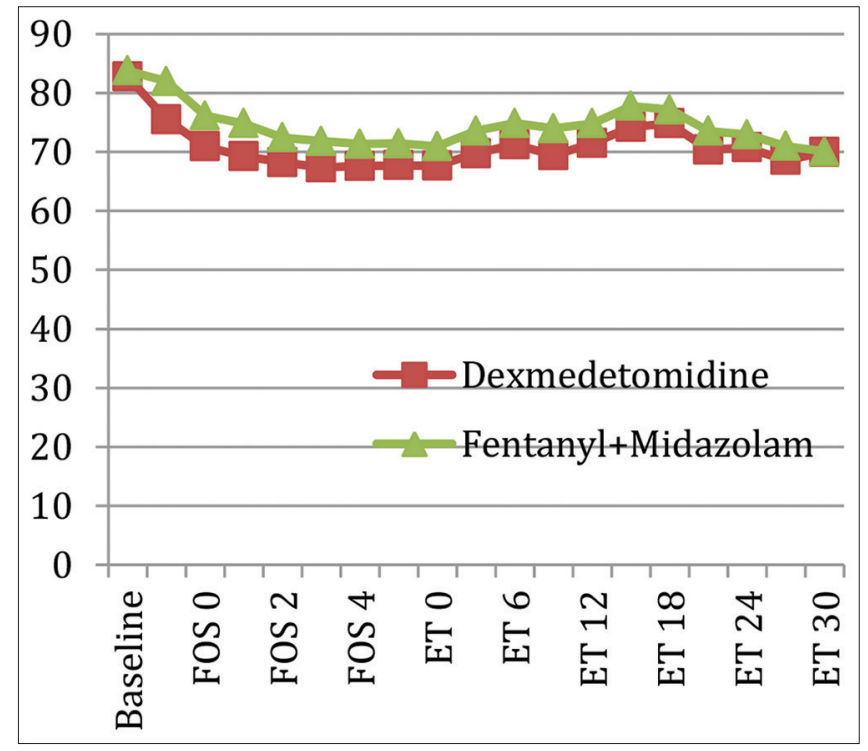

Figure 3: Comparison of heart rate in both groups

\section{BASELINE SYSTOLIC BP}

The mean SBP (mean \pm S.D) was $127.33 \pm 2.89$ in group 1 and $127.6 \pm 4.14$ in group 2 . There was no significant difference between the two groups. $(p>0.05)$. (Figure 4)

\section{AT RSS 3}

The mean SBP (mean \pm S.D) was $126 \pm 3.76$ in group 1 and $124.87 \pm 3.47$ in group 2. Compared with baseline, the mean SBP decreased by $1.26 \mathrm{~mm} \mathrm{Hg}$ in the dexmedetomidine group and $2.73 \mathrm{~mm} \mathrm{Hg}$ in fentanyl and midazolam group. There was no significant difference between the two groups. ( $>>0.05$ ) (Figure 4). Compared with baseline, the mean SBP at the time of insertion of fiberoscope $(0 \mathrm{~min})$ decreased by $8.86 \mathrm{~mm} \mathrm{Hg}$ in the dexmedetomidine group $(\mathrm{p}=0.014)$ and $10.2 \mathrm{~mm} \mathrm{Hg}$ in fentanyl and midazolam group $(p<0.001)$.No significant difference was found in the SBP measurements during FOS between the two groups. $(\mathrm{p}>0.05)$ (Figure 4)

Compared with baseline, the mean SBP at the time of intubation ( $0 \mathrm{~min}$ ) decreased by $18.73 \mathrm{~mm} \mathrm{Hg}$ in the dexmedetomidine group and $19.80 \mathrm{~mm} \mathrm{Hg}$ in fentanyl and midazolam group. On comparison between the 2 groups, no significant difference was found in the SBP measurement after intubation between the two groups. $(\mathrm{p}>0.05)$ (Figure 4).

\section{BASELINE DIASTOLIC BP}

The mean DBP (mean \pm S.D) at baseline was $82.80 \pm 3.66$ in group 1 and $81.60 \pm 3.72$ in group 2 . There was no significant difference between the two groups. ( $>>0.05)$. (Figure 5). 


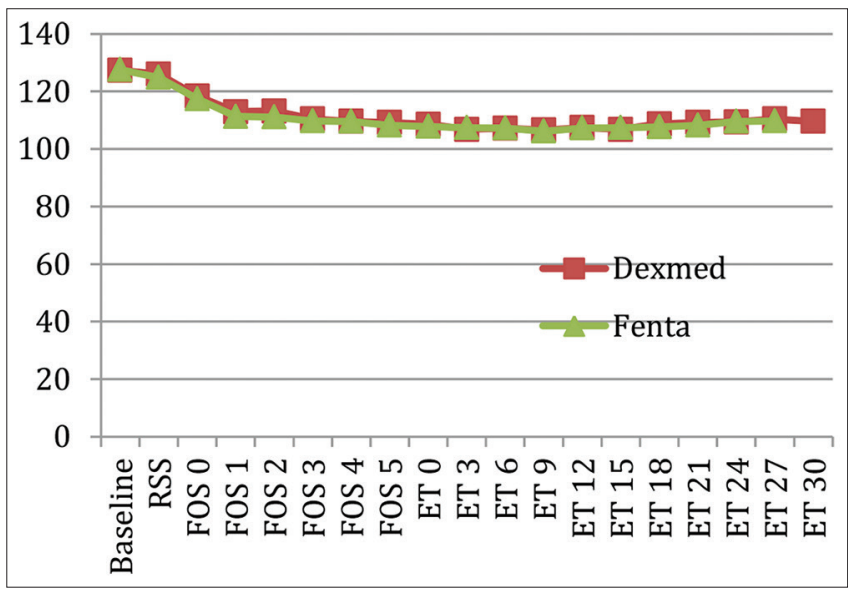

Figure 4: Comparison of systolic blood pressure in both groups

\section{AT RSS 3}

The mean DBP (mean \pm S.D) at RSS 3 was $76.73 \pm 2.85$ in group 1 and $76.13 \pm 2.72$ in group 2. Compared with baseline, the mean DBP decreased by $6.06 \mathrm{~mm} \mathrm{Hg}$ in the dexmedetomidine group and $5.46 \mathrm{~mm} \mathrm{Hg}$ in fentanyl and midazolam group. There was no significant difference between the two groups. ( $>00.05)$. (Figure 5).

Compared with baseline, the mean SBP at the time of insertion of fiberoscope (0 min) decreased by $7.20 \mathrm{~mm}$ $\mathrm{Hg}$ in the dexmedetomidine group and $6.20 \mathrm{~mm} \mathrm{Hg}$ in fentanyl and midazolam group. No significant difference was found in the DBP measurements before intubation between the two groups. ( $p>0.05)$ (Figure 5).

Compared with baseline, the mean DBP at the time of intubation ( $0 \mathrm{~min}$ ) decreased by $14.4 \mathrm{~mm} \mathrm{Hg}$ in the dexmedetomidine group and $13 \mathrm{~mm} \mathrm{Hg}$ in fentanyl and midazolam group. On comparison between the 2 groups, no significant difference was found in the DBP measurement after intubation between the two groups. ( $>>0.05)$ (Figure 5).

\section{BASELINE SpO2}

The mean SpO2 (mean \pm S.D) was $99.87 \pm 0.34$ in group 1 and $99.73 \pm 0.58$ in group 2. There was no significant difference between the two groups. ( $p>0.05)$. (Figure 6).

\section{AT RSS 3}

The mean SpO2 (mean \pm S.D) was $97.67 \pm 2.24$ in group 1 and $95.47 \pm 2.51$ in group 2 . There was significant difference between the two groups. $(p<0.05)$. (Figure 6) Significant difference was found in the SpO2 measurements before intubation between the two groups. $(p<0.05)$ (Figure 6) Significant differences were found in the SpO2 measurements after endotracheal intubation between the two groups upto $18 \mathrm{mins}(\mathrm{p}<0.05)$. No significant difference was found after 15 mins $(\mathrm{P}>0.05)$. (Figure 6).

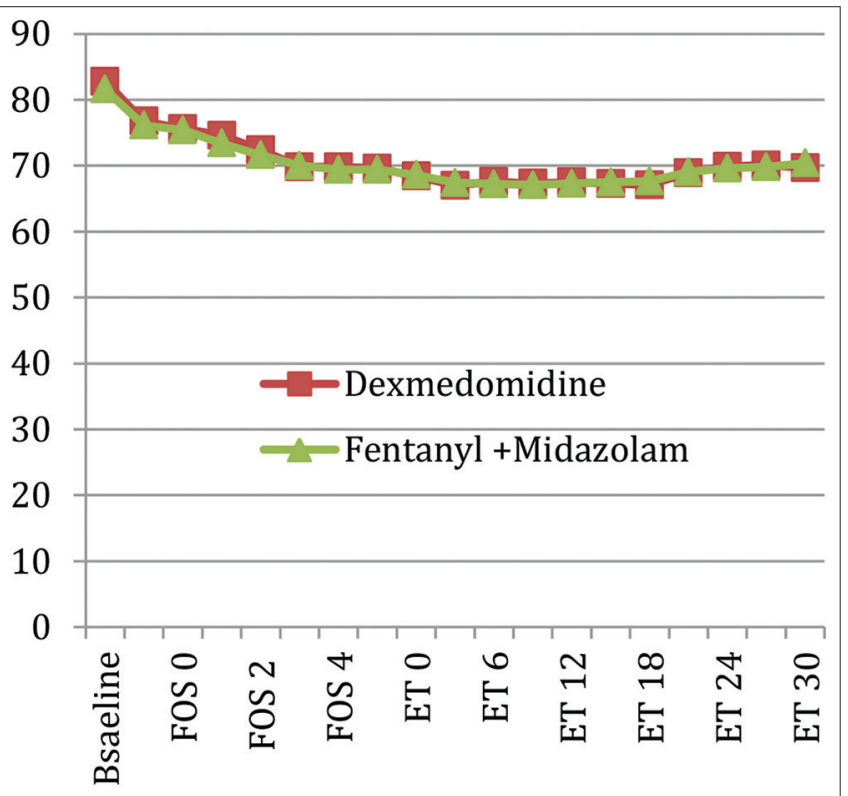

Figure 5: Comparison of diastolic blood pressure in both groups

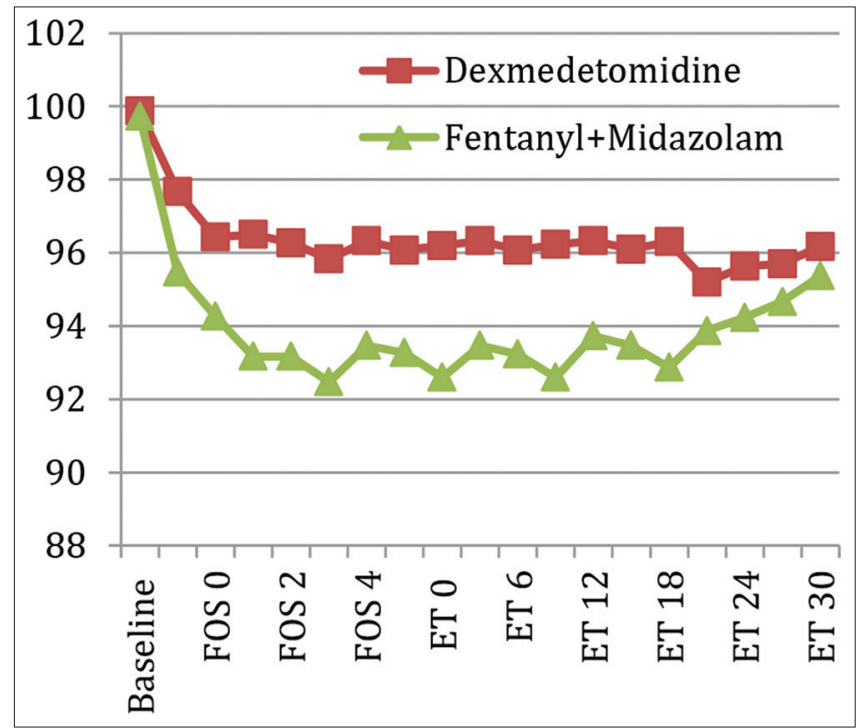

Figure 6: Comparison of oxygen saturation in both groups

\section{RESULTS}

Both groups were comparable demographically in terms of mean age, weight, and M: F. Both groups underwent uncomplicated AFOI. Measurements of the HRs in the two groups showed significant differences between the two groups at RSS-3, during FOS and post-intubation with the DEX group showing lower mean HRs compared with the MDZ and fentanyl group.

SBP and DBP showed a fall in both the groups as compared with the baseline at RSS-3, during FOS and post intubation; however, no significant differences were noted between 
the two groups. Hypotension and bradycardia, the two common side effects of DEX, were not observed in our study probably because the patients were received glycopyrrolate as premedication.

The mean $\mathrm{SpO}_{2}$ values show significant difference between the two groups. $(\mathrm{P}<0.05)$ at RSS-3, FOS, post intubation upto $18 \min (\mathrm{P}<0.05)$.

\section{DISCUSSION}

Fibreoptic intubation is a wonderful technique for securing airway in both anticipated and unanticipated difficult airways. ${ }^{9,10}$

Tolerability of the procedure by the patients during awake intubation requires good topicalization as well as adequate sedation. Inadequate sedation can be devastating as it could lead to exaggerated hemodynamic response to intubation. On the other hand sedation in excess can lead to airway collapse and therefore hypoxia. ${ }^{11}$ Sedation offered by DEX is unique where patients remain sleepy but are arousable. DEX is a highly selective, centrally acting $\alpha 2$ agonist producing hypnosis, amnesia, analgesia, anxiolysis, sympatholysis, and antisialogogue effects all of which are desirable during AFOI. Its sedative properties are mediated by locus ceruleus $\alpha 2$ receptors while spinal alpha- 2 receptors mediate analgesic effects. ${ }^{12,13}$ Post-synaptic alpha-2 receptors in the central nervous system and presynatic alpha- 2 receptors in the peripheral nervous system mediate cardiovascular effects of this drug.

A combination of fentanyl and MDZ for AFOI has good acceptability but risk of fall in $\mathrm{SpO}_{2}$ is reported in literature.

In our study DEX at $1 \mathrm{mcg} / \mathrm{kg}$ bolus infusion over $10 \mathrm{~min}$, with maintenance rates of $0.1-0.7 \mu \mathrm{g} / \mathrm{kg} / \mathrm{h}$, is proved to be safer and beneficial for patients undergoing AFOI. DEX appeared to offer better tolerance, preservation of a patent airway, and spontaneous ventilation, while maintaining hemodynamic stability. The patients in DEX group had a lower mean HR as compared to fentanyl and MDZ group at RSS-3, during fibrescope insertion and post endotracheal tube placement. However, in none of our patients significant bradycardia is noted probably due to glycopyrrolate premedication. Reasons for bradycardia due to DEX as explained in literature are the baroreceptor response of high vascular tone, increased vagal tone that occurs with the bolus, and decreased circulating levels of norepinephrine. ${ }^{14}$

Bloor et al., initially demonstrated the negative chronotropic action of DEX in $1992 .{ }^{15}$ Findings of our study are corroborated by Jain et al., Kharwar et al., comparing attenuation of hemodynamic response with DEX versus fentanyl in 60 patients and demonstrated lower HR with DEX. ${ }^{16,17}$

Gandhi et al., compared DEX with fentanyl in attenuation of pressor response during intubation among 100 patients and observed that the HR was significantly lower in DEX group and the difference persisted for $10 \mathrm{~min}$ after intubation. These findings are in concordance with our results. ${ }^{18}$

DEX is reported to have dose-dependent biphasic response in blood pressure. ${ }^{19}$ Direct stimulation of alpha-2 receptors on blood vessels leads to hypertension with higher doses. On the other hand, hypotension is due to inhibition of the release of norepinephrine from sympathetic nerve terminals by lower doses. ${ }^{20}$ However, the typical biphasic response was not noted in our study. Jorden et al., also observed that high bolus doses of DEX do not always result in hypertension, ${ }^{14}$ while Venn et al., ${ }^{21}$ reported that high doses of DEX may be used safely without changes in hemodynamics when they are infused slowly over $10 \mathrm{~min}$. However in our study, no significant changes were found in systolic as well as diastolic blood pressure. Combination of MDZ with opioids for sedation during AFOI poses a significant risk of desaturation, cessation of respiration, airway collapse which may even lead to aspiration. ${ }^{22,23}$

Mondal et al., compared intubating conditions and degree of desaturation between DEX and fentanyl in 60 patients and observed higher incidence of desaturation with fentanyl than with DEX. ${ }^{8}$

Similarly Agrawal et al., also compared DEX versus fentanyl and MDZ combination as sedative adjunct to fibreoptic intubation under topical anaesthesia and observed that respiratory rate and $\mathrm{SpO}_{2}$ were significantly lower in fentanyl plus MDZ group before intubation. ${ }^{24}$

\section{CONCLUSION}

The use of DEX at $1 \mathrm{mcg} / \mathrm{kg}$ bolus slowly over $10 \mathrm{~min}$, with maintenance rates of $0.1-0.7 \mu \mathrm{g} / \mathrm{kg} / \mathrm{h}$, is safe and beneficial for patients undergoing AFOI. Thus, DEX acts like an ideal drug for AFOI. It provides excellent intubating conditions without significant hemodynamic perturbations and risk of hypoxia.

\section{ACKNOWLEDGEMENT}

We would like to thank the department of Anaesthesia. Government Medical. College, Patiala for allowing us to conduct this study. 


\section{REFERENCES}

1. Reid LC, Brace DE. Irritation of the respiratory tract and its reflex effect upon heart .Surg Gynaec \&Obst;1940;70:157-62.

2. Prys-Roberts C, Greene LT, Meloche R and Foex P. Studies of anaesthesia in relation to hypertension. Haemodynamics consequences of induction and endotracheal intubation. $\mathrm{Br} \mathrm{J}$ Anaesth. 1971;43(6):531-547.

https://doi.org/10.1093/bja/43.6.531

3. Xue FS, Zhang GH, Sun HY, Li CW, Li P, Sun HT, et al. Blood pressure and heart rate changes during intubation: A comparison of direct laryngoscopy and a fibreoptic method. Anaesthesia. 2006;61(5):444-448.

https://doi.org/10.1111/j.1365-2044.2006.04584.x

4. Szmuk P, Erzi T, Evron S, Roth $Y$ and Katz J. A brief history of tracheostomy and tracheal intubation, from the Bronze age to the Space age. Intensive care med. 2007;34(2):222-228.

https://doi.org/10.1007/s00134-007-0931-5

5. Radomski T. Manual Garcia (1805-1906): A bicentenary reflection. Aust Voice. 2005;11:25-41.

6. JSTOR, Organization. Proceedings of the Royal Society of London. Vol. 7. London: Proceedings of the Royal Society of London, 1856. p. 399-410.

7. Alberti PW. The history of laryngology: A centennial celebration. Otolaryngol Head Neck Surg. 1996;114(3):345-354 https://doi.org/10.1016/s0194-5998(96)70202-4

8. Mondal S, Ghosh S, Bhattacharya S, Choudhury B, Mallick S and Prasad A. Comparison between dexmedetomidine and fentanyl on intubation conditions during awake fiberoptic bronchoscopy: A randomized double-blind prospective study. J Anaesthesiol Clin Pharmacol. 2015;31(2):212-216.

https://doi.org/10.4103/0970-9185.155151

9. Drolet P. Management of the anticipated difficult airway a systematic approach: Continuing professional development. Can J Anaesth. 2009;56(9):683-701.

https://doi.org/10.1007/s12630-009-9144-4

10. Apfelbaum JL, Hagberg CA, Caplan RA, Blitt CD, Connis RT, Nickinovich DG, et al. Practice guidelines for management of the difficult airway: An updated report by the American society of anesthesiologists task force on management of the difficult airway. Anesthesiology. 2013;118(2):251-270.

https://doi.org/10.1097/aln.0b013e31827773b2

11. Leslie $D$ and Stacey M. Awake intubation. Contin Educ Anaesth Crit Care Pain. 2015;15:64-67.

12. Scheinin $M$ and Schwinn DA. The locus coeruleus. Site of hypnotic actions of alpha 2-adrenoceptor agonists? Anesthesiology. 1992;76(6):873-875.

https://doi.org/10.1097/00000542-199206000-00001
13. Ebert TJ, Hall JE, Barney JA, Uhrich TD and Colinco MD. The effect of increasing plasma concentrations of dexmedetomidine in humans. Anesthesiology. 2000;93(2):382-394. https://doi.org/10.1097/00000542-200008000-00016

14. Jorden VS, Pousman RM, Sanfor MM, Thorborg PA and Hutchens MP. Dexmedetomidine overdose in the perioperative setting. Ann Pharmacother. 2004;38(5):803-807. https://doi.org/10.1345/aph.1d376

15. Bloor BC, Ward DS, Belleville JP and Maze M. Effects of intravenous dexmedetomidine in humans II. Hemodynamic changes. Anesthesiology. 1992;77(6):1134-1142. https://doi.org/10.1097/00000542-199212000-00014

16. Jain V, Chandak A, Ghosh A and Golhar M. Comparison of dexmedetomidine and fentanyl for attenuation of the hemodynamic response to laryngoscopy and tracheal intubation. Ain Shams J Anaesthesiol. 2015;8(2):236-243. https://doi.org/10.4103/1687-7934.156699

17. Kharwar RK, Kumar M, Tiwary PK, Suwalka U and Prakash S. A comparison of intravenous dexmedetomidine V/S Inj. fentanyl for attenuation of hemodynamic responses during laryngoscopy and intubation after propofol induction. Natl $\mathrm{J}$ Integr Res Med. 2014;5(3):71-75.

18. Dhi S, Goyal V, Radhakrishnan K and Balakrishnan M. Comparison of dexmedetomidine with fentanyl in attenuation of pressor response during laryngoscopy and intubation. IOSR J Pharm. 2014;4(2):28-38. https://doi.org/10.9790/3013-040202028-38

19. Bhana N, Goa KL and McCellan KO. Dexmedetomidine. Drugs. 2000;59(2):263-268; discussion 269-270.

20. Ebert T and Maze M. Dexmedetomidine: Another arrow for the clinician's quiver. Anesthesiology. 2004;101(3):568-570. https://doi.org/10.1097/00000542-200409000-00003

21. Venn RM and Grounds RM. Comparison between dexmedetomidine and propofol for sedation in the intensive care unit. Br J Anaesth. 2001;87(5):684-690. https://doi.org/10.1093/bja/87.5.684

22. Bailey PL, Pace NL, Ashburn MA, Moll JW, East KA and Stanley $\mathrm{TH}$. Frequent hypoxemia and apnea after sedation with midazolam and fentanyl. Anesthesiology. 1990;73(5):826-830. https://doi.org/10.1097/00000542-199011000-00005

23. Brock-Utne JG, Winning TJ, Rubin J and Kingston HG. Laryngeal incompetence during neurolept analgesia in combination with diazepam. Br J Anaesth. 1976;48(7):699-701. https://doi.org/10.1093/bja/48.7.699

24. Agrawal A, Jadon A, Parida SS, Chakraborty S, Sinha N and Chandra $\mathrm{O}$. Comparative evaluation of dexmedetomidine and fentanyl midazolam combination as sedative adjunct to fibreoptic intubation under topical anaesthesia. Am J Adv Med Sci. 2014;2(4):29-37.

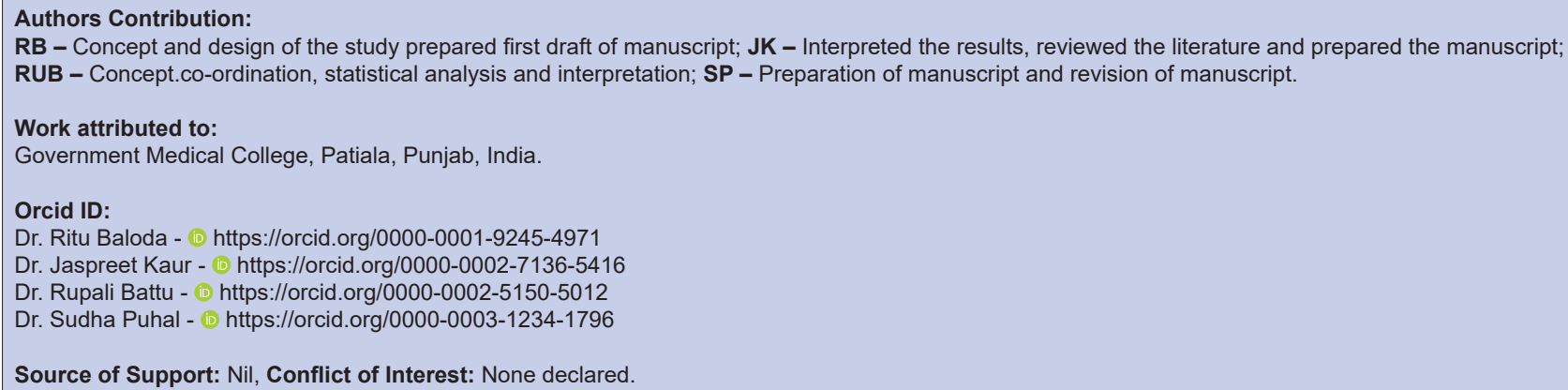

